\title{
Characterisation of Collagen from the Skin of Catfish (Pangasius $s p)$ for Innovative PVA-Collagen Nanofiber
}

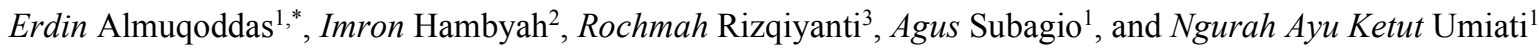 \\ ${ }^{1}$ Physic Department, Science and Mathematics Faculty, Diponegoro University, Semarang - Indonesia \\ ${ }^{2}$ Chemical Engineering Department, Engineering Faculty, Diponegoro University, Semarang - Indonesia \\ ${ }^{3}$ Nursing Department, Medical Faculty, Diponegoro University, Semarang - Indonesia
}

\begin{abstract}
Preparation of PVA-Collagen nanofiber plaster production begin by repairing the skin of catfish, then collagen is extracted with distilled water. Extracted collagen need to be frozen dry so that collagen can be obtained in the form of sheets, powder, or crystals. The next step is the production of PVA-Collagen nanofiber, a $10 \%$ solution of polyvinyl alcohol (PVA) is mixed with a previously prepared extracted collagen and stirred until it forms a homogeneous mixture. Next, PVA-Collagen nanofiber is formed by the electrospinning method. The results of characterization using FTIR found three main groups in six variations: amide group A; amide I; and amide II. Amide A has a wave number in the range 3300-3440 cm1 , amide $\mathrm{I}$ is in the range $1625-1690 \mathrm{~cm}-1$, and amide II is in the range of 1480-1575 cm-1. Characterization was carried out to determine the surface morphology of the observation in the sample using Photomicrograph $(200 \mathrm{~m})$ with magnification 10x, produced fiber diameter formed in variations of PVACollagen 1\% 116-120 $\mathrm{m}$ while in the variation of PVA-Collagen $1 \%+$ Chitosan 10 drops in diameter 41 $50 \mathrm{~m}$.
\end{abstract}

Keywords: Collagen; Nanofiber; Electrospinning.

\section{Introduction}

Skin sores and ulcers from heat, surgery, or diabetes are health problems in the world and have a heavy financial burden on the health care system[1]. Damaged skin will lose its natural protective mechanism and provide an active portal to infect pathogens, causing severe wound infections, thus slowing the healing process of wounds and causing damage and even causing life-threatening complications[2].

Wound care has been developed and plays an important role in healing various wounds[3]. The majority of wound care is made from natural polymers, such as alginate, collagen, chitosan, gelatin and hyaluronic acid[4]. In this case, carboxymethyl chitosan (CMC) and collagen were selected for the preparation of wound dressing substrates because of their excellent biocompatibility, biodegradability and easy modification. In addition, CMC has a remarkable effect in inhibiting bacterial growth and supporting blood coagulation and collagen which can accelerate the process of wound healing[5].

The most common sources of collagen on the market generally come from the skin and bones of animals. One of the aquatic biotas that has the potential as a source of collagen is fish. Filled fish skin from various industrial companies or fish fillet factories is considered a waste product [6] so that the utilization of fish skin as an alternative source of collagen can not only reduce the amount of processing industrial waste, but also increase the added value of the waste. One type of fish that can be used as a source of collagen is catfish[7]. Statistical data from the Ministry of Maritime Affairs and Fisheries (KKP) Republic Indonesia shows that the national production of catfish cultivation is increasing from year to year. The increase in catfish production in 2015 was as much as 339,069 tons and increased to 437,011 tons in 2016, the production of catfish is still increasing where the target of national pangasius production in 2019 is to be 1,149,400 tons (KKP, 2016). This shows great potential for the use of catfish skin (Pangasius sp.) As a source of collagen.

Recently, long-term wound dressing with antimicrobial material has been developed using nanoscale antimicrobial materials. for example, nanosilvers, nano-metal oxides, and carbon nanotubes. The use of this ingredient in wound care can significantly improve the antimicrobial and anti-inflammatory properties and extend the period of antibacterial effects[8]. One of the materials that can be made into the nanoscale is polyvinyl alcohol (PVA) as an additive polymer that aims to produce collagen nanofiber with good biocompatibility and chemical resistance.

Through the preparation of plaster made from PVA-Collagen nanofiber, wound care will be more practical, comfortable and minimize contamination with

\footnotetext{
${ }^{*}$ Corresponding author: erdinalmuqoddas.2017@fisika.fsm.undip.ac.id
} 
the surrounding environment. Thus, the presence of plaster made from collagen and chitosan can be an optimal wound care solution.

In previous studies, plaster can only help as an antimicrobial without any significant wound healing solutions. One solution that can overcome this problem is the use of collagen-based plasters. Collagen is an extracellular matrix protein with the characteristics of increased cell proliferation so that it directly affects physiological and cell morphology. In this research, it was written by collagen extracted from catfish skin waste made into PVA-collagen nanofiber and chitosan as antimicrobial. The biodegradability and biocompatibility properties possessed by collagen and chitosan can minimize the wound healing process.

\section{Materials and Methods}

\subsection{Catfish Skin Preparation}

Fish skin was cut in size by $1 \mathrm{~cm} 2$ and then immersed in $0.1 \mathrm{M} \mathrm{NaOH}$ solution with a ratio of $1: 10(\mathrm{~b} / \mathrm{v})$ for 12 hours at room temperature. $\mathrm{NaOH}$ solution is changed every 2 hours. Then neutralized with distilled water. Then hydrolyzed by immersing in $\mathrm{CH} 3 \mathrm{COOH} 0.3 \mathrm{M}$ for 2 hours a ratio of 1: $6(\mathrm{~b} / \mathrm{v})$. The sample was neutralized using distilled water[9][10].

\subsection{Collagen Extraction}

Samples were extracted using distilled water for 3 hours at $40^{\circ} \mathrm{C}$, comparison of samples and solvents 1: 2 (b / v). The liquid collagen extracted was then freeze-dry and collagen was obtained in powder and crystal form [11].

\subsection{Making PVA-Collagen Nanofiber}

$10 \%$ PVA solution (2 grams of PVA powder plus aquades to a volume of $15 \mathrm{~mL}$ ) was made at a temperature of $80-90{ }^{\circ} \mathrm{C}$ and homogenized using a magnetic stirrer for 2 hours. Next, the collagen solution is $8 \%, 1 \%(0.8 ; 1$ gram of collagen crystal, each added with distilled water containing $0.5 \mathrm{M}$ acetic acid to a volume of $10 \mathrm{~mL}$ ) is made and stirred with a magnetic stirrer for 2 hours. Then, the two solutions are mixed and stirred using a magnetic stirrer for 3 hours on each variable of collagen solution. In addition, for a variation of $8 \%$ and $1 \%$ PVA-Collagen solution $2 \%$ chitosan is added to each solution. Furthermore, the homogeneous PVA-collagen solution is injected[12][13] into the Electrospinning syringe. The distance of the tip of the syringe to the collector wire is $10 \mathrm{~cm}$. The spinneret (jet) hole is set at a diameter of $0.5 \mathrm{~mm}$ with the speed of spraying at $1.2 \mathrm{~mL} /$ hour. The electricity voltage is $25 \mathrm{kV}$ then the PVA-Collagen nanofiber produced is accommodated in the collector wire $[14,15]$.

\subsection{Characterization of PVA-Collagen Nanofiber}

The feasibility of physical or mechanical properties of PVA-Collagen nanofiber was carried out by Fourier Transform Infrared (FTIR, Digilib FTS7000) analysis so that the functional groups contained therein were known. Surface morphology of PVA-Collagen nanofiber can be determined by Scanning Electron Microscope (SEM, Zeiss Ultra 60 FE-SEM) analysis. PVA-Collagen Nanofiber with the best physical, chemical and morphological properties will be used as the main ingredient in the manufacture.

\section{Results and discussion}

\subsection{Skin Extraction of Catfish}

Catfish are cleaned of meat that attaches to the skin of fish and is dried under the hot sun, after the dried fish skin the next process is the skin is cut into pieces with a size of 1-3 mm. fish skin will be weighed using digital scales. In $5 \mathrm{~kg}$ of catfish only 26.5 grams of skin. Furthermore, the skin was soaked in $0.1 \mathrm{M} \mathrm{NaOH}$ solution with a ratio of $1: 10(\mathrm{~b} / \mathrm{v})$ for 12 hours at room temperature. $\mathrm{NaOH}$ solution is changed every 2 hours. Then neutralized with distilled water. Then hydrolyzed by immersing in $\mathrm{CH} 3 \mathrm{COOH} 0.3 \mathrm{M}$ for 2 hours a ratio of 1: $6(\mathrm{~b} / \mathrm{v})$. The sample was neutralized using distilled water.

The extraction process is of two kinds with acidification and the use of pepsin or with enzymatic help. For this study, the acidification technique was used because it was easier and the process was not long, this extraction was carried out for 3-4 days. Fish skin soaked in $\mathrm{NaOH}$ to remove non-protein elements in the skin of catfish, then the fish enters the process.

Acidification uses acetic acid which functions to change the structure of the catfish skin to become softer. In addition, the addition of acetic acid can easily break collagen bonds.

Table 1. Shows the Collagen Chemical Collagen Composition

\begin{tabular}{|r|l|l|l|}
\hline No & Analysis & $\begin{array}{l}\text { Value } \\
(\%) \\
\text { Catfish } \\
\text { Collagen }\end{array}$ & $\begin{array}{l}\text { Collagen } \\
\text { Quality } \\
\text { Requirements }\end{array}$ \\
\hline 1 & Water & 7,01 & $\leq 12$ \\
\hline 2 & Ash & 3,38 & $\leq 1,0$ \\
\hline 3 & Protein & 86,40 & $\geq 75$ \\
\hline 4 & Fat & 0,35 & - \\
\hline
\end{tabular}

Samples were extracted using distilled water for 3 hours at $40^{\circ} \mathrm{C}$, comparison of samples and solvents 1: 2 (b/v). The liquid collagen extracted was then freeze-dry and collagen was obtained in powder form. In this process, the formed collagen will be tested for morphology using FTIR to determine the structure of collagen formed. 


\subsection{Making Nanofiber}

In the initial stage of this research is to prepare the catfish skin, after the extraction process carried out with an acid-base approach it will get catfish collagen which is formed from 50 grams of catfish skin to produce collagen with a weight of 24.6 grams of pure collagen of catfish. Furthermore, collagen formed will enter the stage of making nanofiber.

The first step is to make a solution of PVA solution with a concentration of $10 \%$ (for variations added by collagen $8 \%$ and $1 \%$ without chitosan and $8 \%, 1 \%$ with an additional $2 \%$ chitosan 10 drops). The two solutions were mixed to produce 4 variations: PVA-collagen $8 \%$; PVA-collagen $1 \%$; PVA-collagen $8 \%+2 \%$ Chitosan 10 drops; and PVA-Collagen 1\% $+2 \%$ Chitosan 10 drops. The selection of these concentrations is the optimal result in the manufacture of nanofibers. In a solution with a high concentration, it will cause a difficult solution to flow in the needle. This is due to evaporation that occurs in solvents that have a low evaporation temperature. When the electrospinning process takes place, the solution that is supposed to form Taylor's cone and move towards the collector to form fibers actually undergoes drying and lags behind the tip of the needle so it is difficult to maintain a constant flow and inhibit the solution from the tip of the needle.

The solution which has been varied is then converted into fiber using the electrospinning method. The electrospinning process is carried out at a distance between the collector and the tip of the needle $10 \mathrm{~cm}$. the collector used is made of aluminum plate with a thickness of $2 \mathrm{~mm}$. The voltage given is $25 \mathrm{~V}$, at a high voltage, it will create a strong electric field to pull the solution surface at the tip of the needle when the spinning process takes place so that Taylor cones are formed.

\subsection{Optical Analysis and Characterization of PVA-Collagen Nanofiber}

\subsubsection{Results of Fourier Transform Infrared (FTIR) Analysis}

FTIR characterization was carried out to determine the functional groups in the formed nanofiber. Each absorption at a certain wavelength illustrates the existence of a specific functional group. When a material is irradiated with infrared radiation, there will be an interaction in the form of absorption of energy by the atoms or molecules of the material. The absorption of infrared radiation energy causes an increase in the amplitude of the vibrations of atoms in a molecule.

In (Figure 1) presenting FTIR sample Polyvinyl Alcohol (PVA) found wave values with an absorption area of $2900-3000 \mathrm{~cm}^{-1}$ are C-H stretching groups and detected peaks at wavenumbers $2970.60 \mathrm{~cm}^{-1}$. Cluster >CO (aldehyde) detected at peak with wavenumber $1739.63 \mathrm{~cm}^{-1}$. With a peak area of $1720-1740 \mathrm{~cm}^{-1}$. Cluster -CNO2 (aromatic nitro) is detected with wavenumber $1367.58 \mathrm{~cm}^{-1}$ with an absorption area of
$1300-1570 \mathrm{~cm}^{-1}$. The C-O stretching group was detected at the peak with wavenumber $1216.61 \mathrm{~cm}^{-1}$ and the absorption area at wavenumber $1225-950 \mathrm{~cm}^{-1}$.

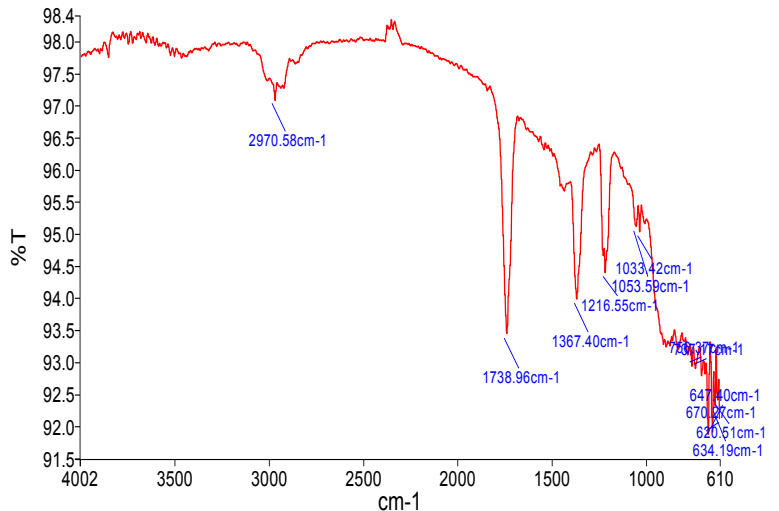

Fig. 1. FTIR Polyvinyl Alcohol Spectrum (PVA)

Figure 2 is a spectrum of PVA fibers plus $2 \%$ Chitosan as a result of the electrospinning process. Shows little effect on changes in wavenumbers that are read in FTIR.

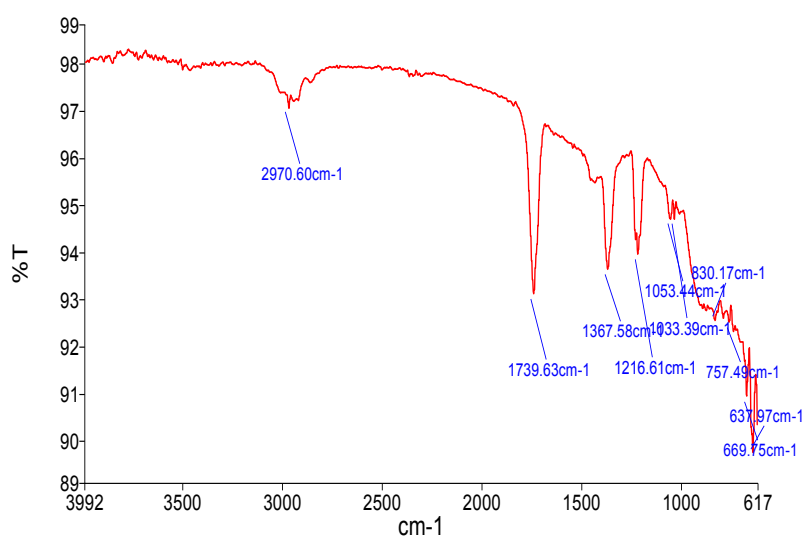

Fig. 2. 2\% FTIR PVA-Chitosan spectrum

Figure 3 is a spectrum of $0.8 \%$ PVA-Collagen fiber and Figure 3 and figure 4 spectrum of 1\% PVA-collagen fiber as a result of the electrospinning process. The results of the absorption analysis of PVA-Collagen fiber $0.8 \%$ (Figure 3) showed the presence of $\mathrm{O}-\mathrm{H}$ stretching and $\mathrm{N}-\mathrm{H}$ stretching functional groups at wavenumbers $3461.63 \mathrm{~cm}^{-1}$. Cluster $\mathrm{C}=\mathrm{C}$ stretching and $\mathrm{C}=\mathrm{O}$ at wave number $1640.82 \mathrm{~cm}^{-1}$. Cluster -C-NO2 (Nitro Aromatic) at wave number $1542.17 \mathrm{~cm}^{-1}$. The results of the absorption analysis of PVA-Collagen 1\% fiber (Figure 4) showed the presence of O-H stretching and N$\mathrm{H}$ stretching functional groups at wave number 3460.37 $\mathrm{cm}^{-1}$. Cluster $>\mathrm{CO}$ (aldehyde) at wave number 1738.47 $\mathrm{cm}^{-1}$. Cluster $\mathrm{C}=\mathrm{C}$ stretching and $\mathrm{C}=\mathrm{O}$ at number $1637.74 \mathrm{~cm}^{-1}$. Cluster -CNO2 (Nitro aromatic) at wave $1368.53 \mathrm{~cm}^{-1}$. The C-O stretching group is detected at the peak with wavenumber $1216.50 \mathrm{~cm}^{-1}$. 


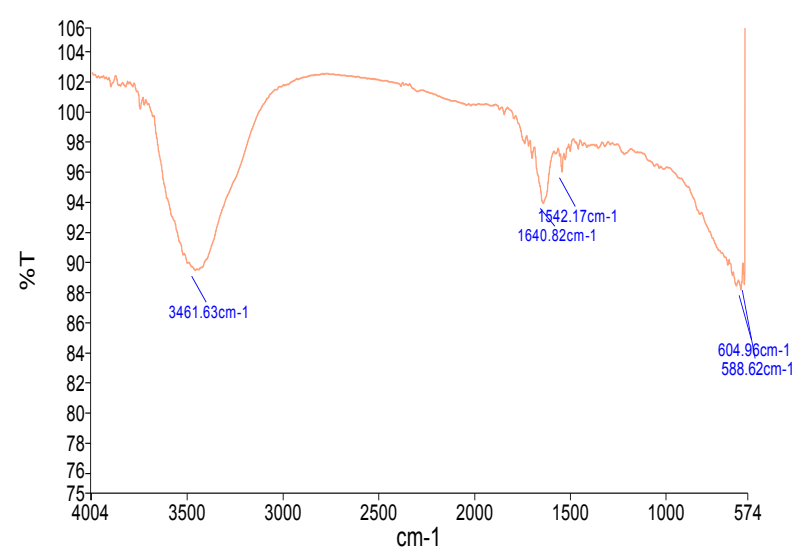

Fig. 3. PVA-Collagen Spectrum $0.8 \%$

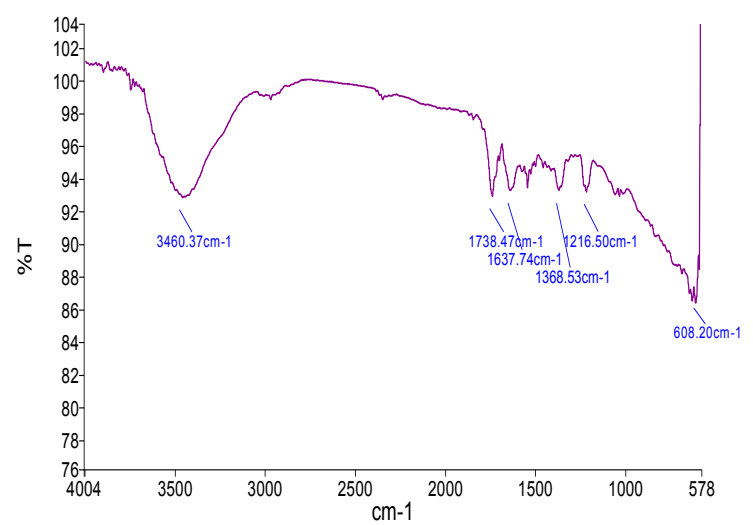

Fig. 4. 1\% FTA PVA-Collagen Spectrum

Samples on PVA-Collagen fiber $(0,8 \%$ and $1 \%$ plus $2 \%$ Chitosan) from electrospinning for other variations, the results of analysis of uptake of $0,8 \%$ PVA-Collagen fiber plus Chitosan 2\% (Figure 5) showed $\mathrm{OH}$ functional groups stretching and $\mathrm{NH}$ at wave number $3460.99 \mathrm{~cm}^{-1}$. Cluster $\mathrm{C}=\mathrm{C}$ stretching $\mathrm{C}=\mathrm{O}$ at wave number $1637.64 \mathrm{~cm}^{-1}$. The result of the analysis of absorption of $1 \%$ PVA-Collagen plus $2 \%$ Chitosan (Figure 6) showed the presence of $\mathrm{O}-\mathrm{H}$ stretching and N$\mathrm{H}$ functional groups at wave number $3444.53 \mathrm{~cm}^{-1}$. Function group $>\mathrm{CO}$ (aldehyde) at wave number 1738.83 $\mathrm{cm}^{-1}$. Cluster $\mathrm{C}=\mathrm{C}$ stretching and $\mathrm{C}=\mathrm{O}$ stretching at wave number $1643.43 \mathrm{~cm}^{-1}$. The $-\mathrm{CNO}_{2}$ (Nitro Aromatic) function groups at wave number $1542.45 \mathrm{~cm}^{-1}$. The value of the wave number in the functional groups formed increases with increasing concentration of the solution. In addition, there is a graph that shows the toughness of absorption when PVA before and after added, even collagen and chitosan. This indicates the presence of identical compounds formed and does not result in the formation of new functional groups.

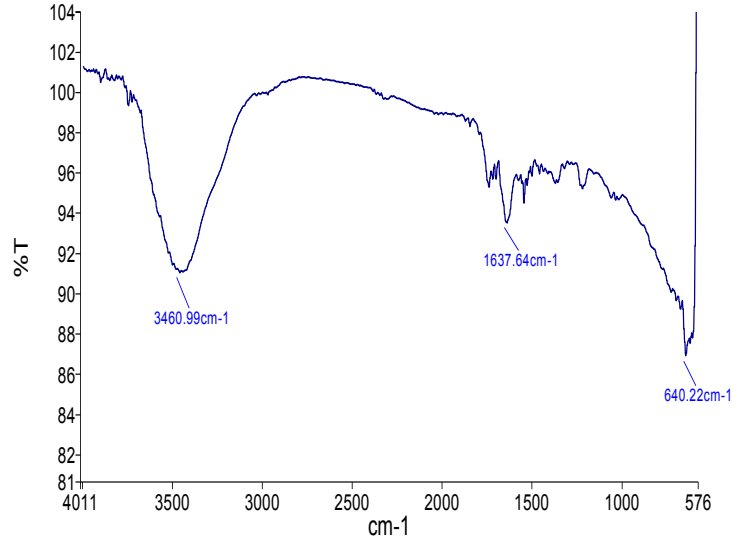

Fig. 5. FTIR Spectrum PVA-Collagen $0.8 \%+$ Chitosan $2 \%$

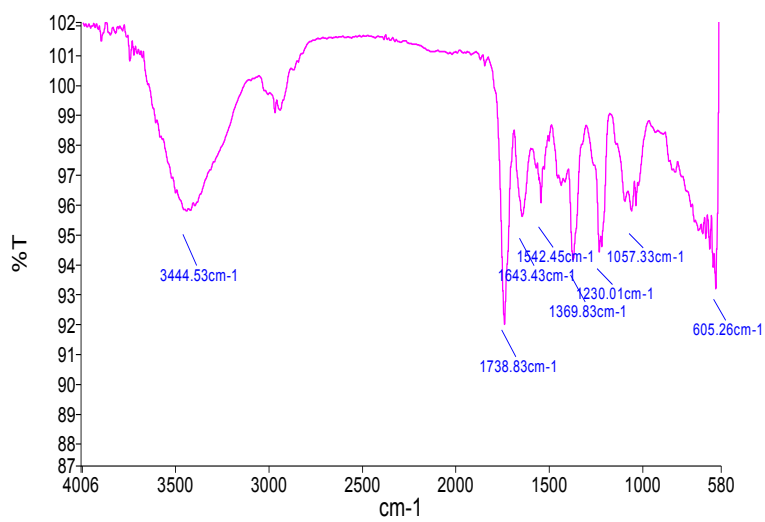

Fig. 6. FTIR Spectrum PVA-Collagen 1\% + Chitosan $2 \%$

\subsubsection{Results of Analysis of Photomicrograph-EDS of PVA-Collagen Nanofiber}

Photomicrograph was carried out to determine the distribution of PVA-Collagen and PVA-Collagen + Chitosan to determine the surface morphology. The fiber tested in this variation is 1\% PVA-Collagen and 1\% PVA-Collagen $+2 \%$ Chitosan, the selection of this varies based on the formed nanofiber has the desired thickness. From the picture you can see the difference before and after adding chitosan, there are differences in thickness and uniformity. Then the samples were observed using Photomicrograph $(200 \mathrm{~m}) 10$ times magnification to determine the size of the diameter, morphology, and structure of the fiber. Diameter of PVA-Collagen $1 \%$ fiber (Figure 7) and PVA-Collagen $1 \%+$ Chitosan $2 \%$ (Figure 9) the image shows that the size of the fiber diameter is influenced by the stress and concentration of the solution. The greater the voltage applied, the smaller the size of the fiber. This is because giving a high voltage will create a strong electric field to pull the solution surface on the spinneret when the spinning process takes place so that Taylor's cone can form. Taylor cones indicate nanosatate formation, so that when the given voltage is higher than the fibers formed are smaller due to the Taylor cone. 


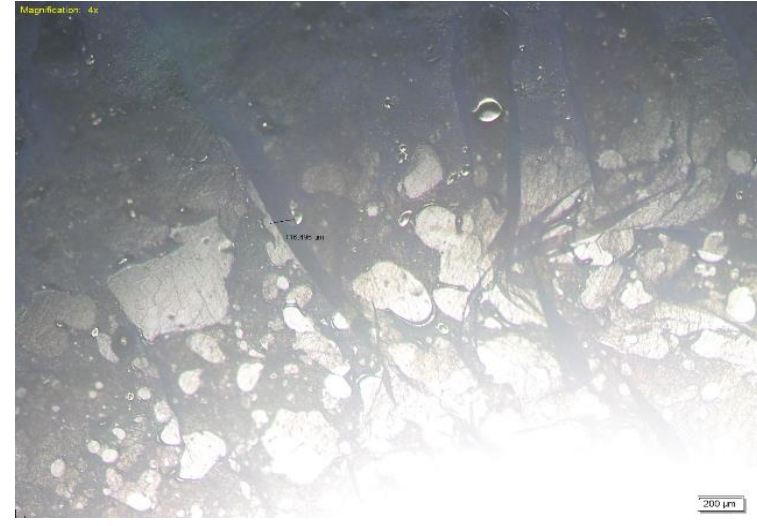

Fig. 7. Shows the results of a $1 \%$ photomicrograph PVACollagen image

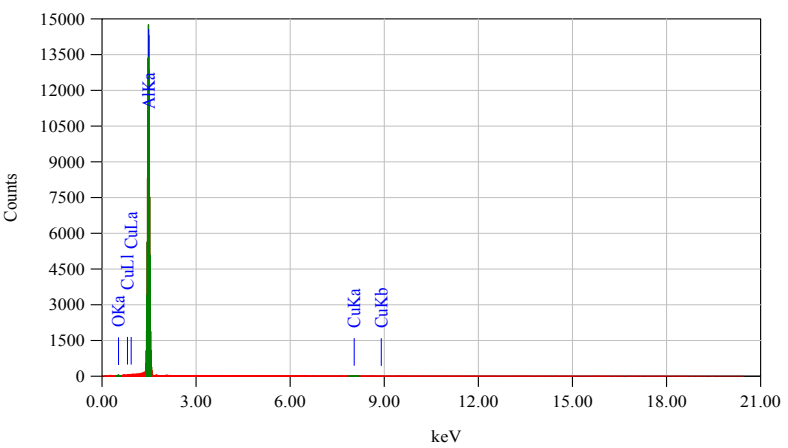

Fig. 8. Shows the results of a 1\% EDS PVA-Collagen image

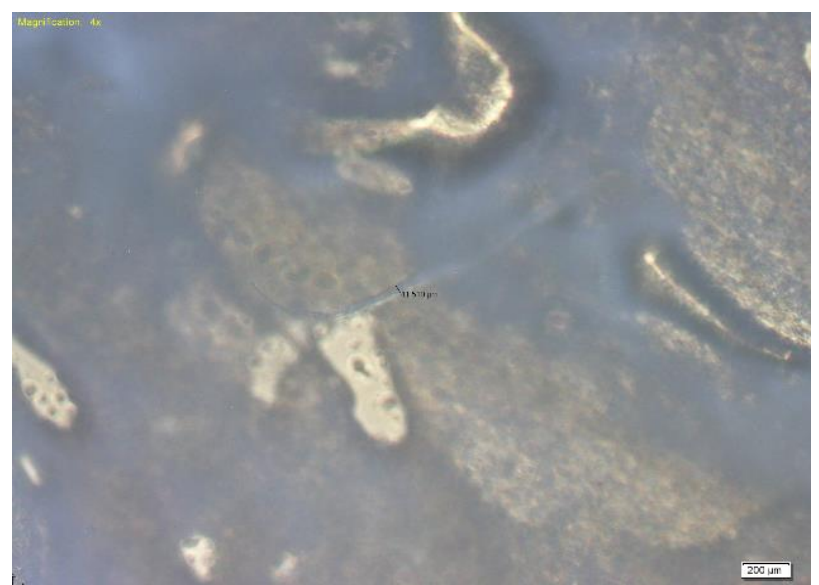

Fig. 9. Shows the results of the photomicrograph PVACollagen $1 \%$ image + Chitosan 10 drops

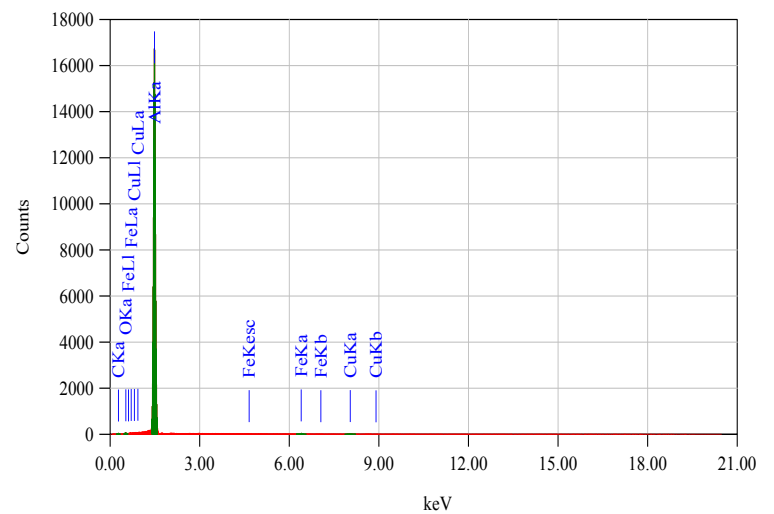

Fig. 10. Shows the results of the photomicrograph PVACollagen 1\% image + Chitosan 10 drops
From the image image it can be seen the fiber diameter formed in the variation of PVA-Collagen 1\% 116-120 $\mathrm{m}$ while in the variation of PVA-Collagen 1\% + Chitosan 10 drops in diameter 41-50 m.

\section{Conclusion}

The catfish collagen produced by the acid-base process will be synthesized into PVA-Collagen nanofiber by electrospinning method by giving two variations of the concentration of collagen solution $0.8 \%$ and $1 \%$ with a voltage of $25 \mathrm{kV}$. The effect of the variation of the collagen concentration given to PVA-Collagen fibers produced a crystalline peak that widened further and lowered the intensity of the peak of Kristalin. The results of the FTIR analysis show that there are identical compounds in the spectrum of PVA and Collagen and no new functional groups occur. The effect of increasing voltage can form fibers with smaller and thinner sizes. The effect of increasing the concentration of the solution decreases the wave number in the functional groups formed, decreases the size of the average fiber diameter, and increases the thickness of the fiber.

The results obtained by the fiber diameter formed in the variation of PVA-Collagen 1\% 116-120 m while in the variation of PVA-Collagen $1 \%+$ Chitosan 10 drops in diameter 41-50 m.

\section{References}

1. F. L. Bowling, S. T. Rashid, and A. J. M. Boulton, Preventing and Treating Foot Complications Associated with Diabetes Mellitus. Nature Reviews Endocrinology, 11(10), 606-616 (2015)

2. N Sudheesh, SK Sharma, RS Shukla, Chitosan as an eco-friendly solid base catalyst for the solvent-free synthesis of jasminaldehyde. Journal of Molecular Catalysis A: Chemical 321 (1), 77-82 (2012)

3. J. Boateng and O. Catanzano, Advanced Therapeutic Dressings for Effective Wound Healing : a Review. Journal of Pharmaceutical Sciences, 104(11), 36533680 (2015)

4. R. Huang, W. Li, X. Lv, Z. Lei, Y. Bian, H. Deng, ... X. Li, Biomimetic LBL Structured Nanofibrous Matrices Assembled By Chitosan/Collagen For Promoting Wound Healing. Biomaterials, 53, 58-75 (2015)

5. D. Govindarajan, N. Duraipandy, K. V. Srivatsan, R. Lakra, P. S. Korapatti, R. Jayavel, and M. S. Kiran, Fabrication of Hybrid Collagen Aerogels Reinforced with Wheat Grass Bioactives as Instructive Scaffolds for Collagen Turnover and Angiogenesis for Wound Healing Applications. ACS Applied Materials \& Interfaces, 9(20), 1693916950 (2017)

6. Nurhayati, Tazwir, Murniyati, Ekstraksi dan Karakterisasi Kolagen Larut Asam dari Kulit Ikan Nila (Oreochromis niloticus). JPB Kelautan dan Perikanan, 8(1):85-92 (2013) 
7. P. Suptijah, D. Indriani, S. E. Wardoyo, Isolasi dan Karakterisasi Kolagen dari Kulit Ikan Patin (Pangasius Sp.), Jurnal Ilmiah Ilmu-Ilmu Biologi dan Kimia, 4(1) (2018)

8. D. Mosselhy, H. Granbohm, U. Hynönen, Y. Ge, A. Palva, K. Nordström, and S.-P. Hannula, Nanosilver-Silica Composite: Prolonged Antibacterial Effects and Bacterial Interaction Mechanisms for Wound Dressings. Nanomaterials, 7(9), 261 (2017)

9. R. Huang, W. Li, X. Lv, Z. Lei, Y. Bian, H. Deng, ... X. Li, Biomimetic LBL Structured Nanofibrous Matrices Assembled By Chitosan/Collagen For Promoting Wound Healing, Biomaterials, 53, 58-75 (2015)

10. Singh Prabjeet, etc. Isolation and characterisation of collagen extracted from the skin of striped catfish (Pangasianodon hypophthalmus) Japan: Elsevier (2010)

11. A. H. Komala, Ekstraksi dan Karakterisasi Kolagen dari Kulit Ikan Patin (Euthynnus Affinis), Departemen Teknologi Hasil Perairan: IPB (2015)

12. Lijun Yang, Wallace Woon-Fong Leung, Improvement of Dye Sensitized Solar Cells with Nanofiber-Based Anode, ASME 2011 International Mechanica/ Engineering Congress and Exposition (IMECE2011), November 11- 17, 2011, Denver, Colorado, USA (2011)

13. A.N. Pickett, Electrospinning Applications in Mechanochemistry and Multifunctional Hydrogel Materials (2012)

14. K. D. Adistiana, Sintesis Nanofiber dari Polivinil Alkohol (PVA)- Kolagen Menggunakan Metode Electrospinning. Departemen Fisika : IPB (2017).

15. R. Khajavi, M. Abbasipour, A. Bahador, Electrospun Biodegradable Nanofibers Scaffolds for Bone Tissue Engineering, J. Appl. Polym. Sci. (2016) 